\title{
Adherence of Streptococcus mutans to Fiber-Reinforced Filling Composite and Conventional Restorative Materials
}

\author{
Lippo V.J. Lassila, Sufyan Garoushi*, Johanna Tanner, Pekka K.Vallittu and Eva Söderling \\ Department of Prosthetic Dentistry \& Biomaterials Science, Institute of Dentistry, University of Turku, Turku, Finland
}

\begin{abstract}
:
Objectives. The aim was to investigate the adhesion of Streptococcus mutans (S. mutans) to a short glass fibers reinforced semi-IPN polymer matrix composite resin. The effect of surface roughness on adhesion was also studied. For comparison, different commercial restorative materials were also evaluated.

Materials and Methods. Experimental composite FC resin was prepared by mixing $22.5 \mathrm{wt} \%$ of short E-glass fibers, 22.5 $\mathrm{wt} \%$ of IPN-resin and $55 \mathrm{wt} \%$ of silane treated silica fillers using high speed mixing machine. Three direct composite resins (Z250, Grandio and Nulite), resin-modified glass ionomers (Fuji II LC), amalgam (ANA 2000), fiber-reinforced composite (FRC) (everStick and Ribbond), and pre-fabricated ceramic filling insert (Cerana class 1) were tested in this study. Enamel and dentin were used as controls. The specimens (n=3/group) with or without saliva were incubated in a suspension of $S$. mutans allowing initial adhesion to occur. For the enumeration of cells on the disc surfaces as colony forming units (CFU) the vials with the microbe samples were thoroughly Vortex-treated and after serial dilutions grown anaerobically for 2 days at $+37^{\circ} \mathrm{C}$ on Mitis salivarius agars (Difco) containing bacitracin. Bacterial adhesion was also evaluated by using scanning electron microscopy. Surface roughness $(\mathrm{Ra})$ of the materials was also determined using a surface profilometer. All results were statistically analyzed with one-way analysis of variance (ANOVA).

Results. Composite FC resin and other commercial restorative materials showed similar adhesion of $S$. mutans, while adhesion to dentin and enamel was significantly higher $(\mathrm{p}<0.05)$. Surface roughness had no effect on bacterial adhesion. Saliva coating significantly decreased the adhesion for all materials $(\mathrm{p}<0.05)$. Composite FC resin had a significantly higher Ra value than control groups $(\mathrm{p}<0.05)$.

Conclusions. Short fiber-reinforced composite with semi-IPN polymer matrix revealed similar S. mutans adhesion than commercial restorative materials.
\end{abstract}

Keywords: Bacterial adhesion, surface roughness, fiber composite resin, restorative materials.

\section{INTRODUCTION}

The increasing attractiveness of tooth coloured restorations has promoted research in this particular area of dental material during last few years. Attempts have been made to change the type of fillers or filler size and their surface silanization, by changing the polymerization kinetics of resins matrices and degree of monomer conversion has tried to be influenced $[1,2]$. Reinforcing the resin with micro-glass fibres [3], with fiber-reinforced composite (FRC) substructure [4,5], whiskers [6], particulate ceramic fillers (dense and porous) [7] and optimization of filler content are among the methods that have been studied $[1,8]$. However, after many significant material improvements restorative composite resin still suffers lack of mechanical properties and problems related to polymerization shrinkage. Such shrinkage induces contraction stress at interface between composite resin and cavity walls leading to gaps formation and secondary caries. This is a major problem in current restorative dentistry. In addition, the rough surface of a restoration increases plaque accumula-

*Address correspondence to this author at the Department of Prosthetic Dentistry and Biomaterials Science, Institute of Dentistry, University of Turku, Lemminkäisenkatu 2, FI-20520 Turku, Finland; Tel: + 358-2-333; Fax: + 358-2-333-83-90; E-mail: sufgar@utu.fi tion, which may result in an increased secondary caries. In vivo and in vitro studies have shown that Streptococcus mutans (S. mutans) is one of the bacteria isolated in plaque samples from natural and artificial surfaces during early stages of caries development $[9,10]$. However, it is well known that the first stage of colonization by an organism involves adherence of the organism to a host surface. From this viewpoint, evaluation of $S$. mutans adhesion and colonization to tooth surfaces and restorative materials are of most importance for their success [9].

Glass fibers have been investigated to reinforce dental polymers for over 30 years [11]. They have documented reinforcing efficiency and good esthetic qualities compared to carbon or aramid fibers [11,12]. Polymethyl methacrylate (PMMA) and dimethacrylate based semi-interpenetrating polymer network (semi-IPN) matrix have been established as a polymer matrix in denture base materials [13]. Also some products of fiber-reinforced composite (FRC) use semi-IPNpolymer in the matrix [14]. Although previous investigations [15-18] on the use of experimental semi-IPN matrix in combination with short E-glass $(2-3 \mathrm{~mm})$ fibers in restorative filling composite show enhancement in flexural strength and load-bearing capacity, the effect of short glass-fiber reinforcement on bacterial adhesion and surface roughness has 
Table 1. Materials Used in the Study

\begin{tabular}{|c|c|c|c|}
\hline Brand & Manufacturer & Lot no. & Composition \\
\hline FC & Experimental short fiber composite & & Look at material part \\
\hline Filtek Z250 & $\begin{array}{l}\text { 3M ESPE Dental products, } \\
\text { St paul, MN, USA }\end{array}$ & 20061003 & $\begin{array}{l}\text { BisGMA, UDMA, } \\
\text { BisEMA }\end{array}$ \\
\hline Grandio & Voco, Cuxhaven, Germany & 630615 & $\begin{array}{l}\text { Aliphatic and aromatic dimethacrylates, } 78 \% \\
\text { by weight filler }\end{array}$ \\
\hline Nulite & Hornsby NSW, Australia & 021703 & BisGMA based hybrid composite resin \\
\hline Fuji II LC & GC corporation, Japan & 5401042 & Resin modified Glass-ionomer cement \\
\hline Amalgam (ANA 2000) & Nordiska Dental AB, Ängelholm, Sweden & $95127-3468$ & Silver, copper, tin, zinc and mercury \\
\hline everStick & StickTeck Ltd, Turku, Finland & 2060727-ES-158 & E-glass fibers, PMMA, BisGMA \\
\hline Ribbond & Ribbond Inc, Seattle, Washington, USA & 9541 & UHMW-polyethylene, BisGMA \\
\hline Cerana class 1 & Nordiska Dental AB, Ängelholm, Sweden & 141002-26XL & Leucite reinforced glass ceramic \\
\hline
\end{tabular}

PMMA, poly methyl methacrylate, $\mathrm{M}_{\mathrm{w}} 220.000$

BisGMA, bisphenol A-glycidyl dimethacrylate.

TEGDMA, triethylenglycol dimethacrylate.

UDMA, urethane dimethacrylate.

BisEMA, bisphenol A polyethylene glycol diether.

UHMW, ultra high molecular weight

not been reported. It has been hypothesized that using isotropic short-fiber fillers will not effect on the surface roughness and bacterial adhesion of composite resin.

Thus, the aim of this study was to compare $S$. mutans adhesion and surface roughness of experimental short glassfiber composite resin with different commercial restorative materials.

\section{MATERIALS AND METHODS}

\subsection{Materials}

Eight commercial restorative materials, three filling composite resins, resin-modified glass ionomers, amalgam, two fiber-reinforced composites and pre-fabricated ceramic filling insert were tested in this study. They are listed in Table 1. Enamel and dentin were used as control groups.

Dimethacrylate (BisGMA 67\% [bisphenol A-glycidyl dimethacrylate] and TEGDMA 33\% [triethylenglycol dimethacrylate]) resin consisting $50 \mathrm{wt} \%$ nanofillers with an approximate diameter of $20 \mathrm{~nm}$ in size $\left(\mathrm{SiO}_{2}\right)$ (Hanse Chemie, Germany) and E-glass fibers with BisGMA-PMMA [polymethylmethacrylate, Mw 220.000]) resin matrix (everStick, StickTech Ltd, Turku, Finland). In addition, radioopacity fillers of $\mathrm{BaAlSiO}_{2}(3 \pm 2 \mu \mathrm{m}$ in size) (Specialty Glass, USA) were incorporated to the resin system. Before the $\mathrm{BaAlSiO}_{2}$ filler particles were incorporated into the resin matrix, they were silane treated using previously reported technique [19].

Experimental fiber composites (FC) were prepared by mixing $22.5 \mathrm{wt} \%$ of silinated short E-glass fibers $(2-3 \mathrm{~mm}$ in length) [15-17] to $22.5 \mathrm{wt} \%$ of resin matrix and then $55 \mathrm{wt} \%$ of $\mathrm{BaAlSiO}_{2}$-radio-opacity-fillers were added gradually to the mixture. The mixing was carried by using high speed mixing machine for 5 min (SpeedMixer, DAC, Germany, $3500 \mathrm{rpm}$ ). The dimethacrylate based resin matrix consisting PMMA forms semi-IPN polymer matrix for the composite of FC.

\subsection{Methods}

Nine specimens for each material $(2 \mathrm{~mm}$-thick disc with a diameter of $6.5 \mathrm{~mm}$ ) were photo-polymerized for $40 \mathrm{~s}$ using a light source with an irradiance of $800 \mathrm{~mW} / \mathrm{cm}^{2}$ (Optilux500, Kerr, CT, USA). After polymerization, specimens were polished by diamond cub (Edenta AG, Switzerland) under water cool using low speed handpiece rotating at approximately $20.000 \mathrm{rpm}$. Discs from enamel and dentin $(\mathrm{n}=9$, control) were obtained from freshly extracted sound third molars using a slow speed diamond saw (Ernst Leitz GMBH, Wetzlar 1600, Germany). Specimens were water stored for $24 \mathrm{~h}$ at $37^{\circ} \mathrm{C}$ before testing.

\section{Measurement of Surface Roughness}

The surface roughness of the specimen $(n=3)$ was measured using a surface profilometer (Mitutoyo surftest 301, Mitutoyo Corporation, Kanagawa, Japan), with a standard cutoff of $0.8 \mathrm{~mm}$, a transverse length of $0.8 \mathrm{~mm}$, and a stylus speed of $0.1 \mathrm{~mm} / \mathrm{s}$. The roughness average $(\mathrm{Ra})$ of a specimen was defined as the arithmetic average height of roughness component irregularities from the mean line measured within the sampling length. Three profilometer tracings were made for each specimen and numerical average was determined for each group.

\section{Preparation of Saliva for the Adhesion Tests}

Paraffin-stimulated saliva was collected from 4 volunteers. The pooled saliva was clarified by centrifugation 


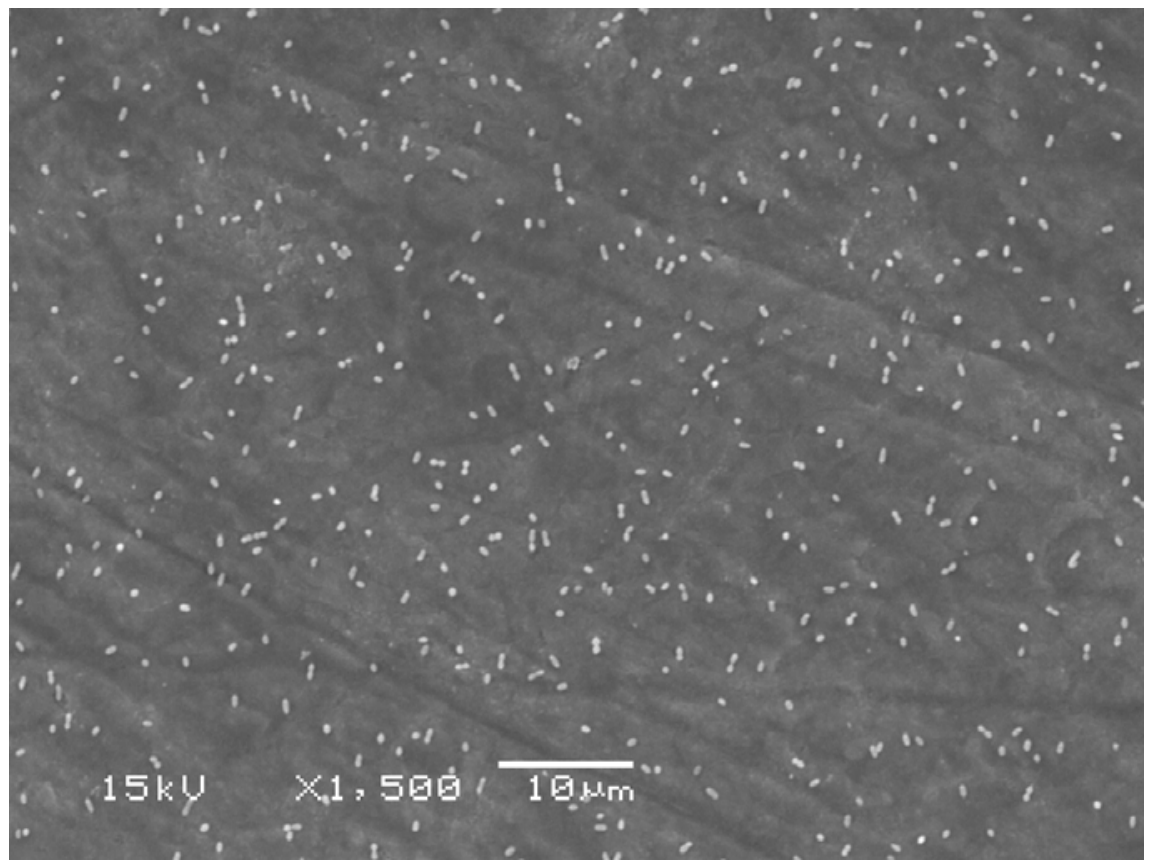

Fig. (1). SEM photograph of saliva coated enamel surface with adhered S. mutans cells.

$(12000 \mathrm{~g}, 10 \mathrm{~min})$, stored in aliquots at $-70{ }^{\circ} \mathrm{C}$. Before use it was thawed and diluted 1:5 with adsorption buffer (see below) [20].

\section{Cultivation of the Microorganism and Preparation of Cell Suspensions}

For the adhesion experiments Streptococcus mutans Ingbritt (kindly provided by Dr. Carlén, University of Göteborg, Sweden) was cultured on blood plates (Orion Diagnostica, Espoo, Finland) for $16 \mathrm{~h}$ at $+37{ }^{\circ} \mathrm{C}$ in an anaerobic athmosphere. In these conditions the cells occur in suspension as singles, pairs or triplets (Fig. 1), which makes further homogenization unnecessary [20]. The cells were harvested from the plates with plastic loops, washed twice $(10000 \mathrm{~g}, 10$ min) with phosphate-buffered saline (PBS; $137 \mathrm{mM} \mathrm{NaCl}$, $10 \mathrm{mM}$ phosphate, $2.7 \mathrm{mM} \mathrm{KCl}, \mathrm{pH} \mathrm{7.4)}$ and suspended in the adsorption buffer to an optical density of $0.35\left(\mathrm{~A}_{550}\right)$ corresponding to $5 \times 10^{8} \mathrm{CFU}$ per $\mathrm{ml}[20]$.

The cell density was checked in preliminary adhesion experiments showing in scanning electron microscopy (SEM) even distribution of the cells on the material surfaces with abundant space for surface colonization (Fig. 1).

\section{Adhesion Tests}

The adhesion experiments were essentially performed as described earlier for granular hydroxyapatite [20]. The discs ( $n=3 /$ group with or without saliva) were first preincubated in $2 \mathrm{ml}$ adsorption buffer/diluted saliva at room temperature for 30 min using gentle rolling (The Coulter Mixer, Luton, UK) in $14 \mathrm{ml}$ capped plastic test tubes with an inner diameter of $16 \mathrm{~mm}$ (Falcon, BD Biosciences, Bedford, MA, USA). The mixer was tilted in a 15 degree angle to ensure that the discs were covered by liquid at all times. After the preincubation the discs were rinsed once in $50 \mathrm{ml}$ saline $(0.9 \% \mathrm{NaCl}$, Orion Diagnostica, Espoo, Finland) and then transferred to test tubes with $2 \mathrm{ml}$ of the cell suspension prepared as described above. The discs were rolled in the cell suspensions for 30 min and then rinsed gently 3 times in $50 \mathrm{ml}$ saline. Thereafter the attached cells from one side of the disc were scraped to $0.5 \mathrm{ml}$ of transport medium (Tryptic Soy Broth, Difco Laboratories, MI, USA). Three applicators dipped into fresh transport medium before the procedure (Quick-Stick, Dentsolv AB, Sweden) were used to scrape the cells from the disc. The brush ends of the applicators were cut into the transport media. In preliminary experiments, one Vortextreatment of the vials efficiently removed the bacteria from the brushes 1 and 2, increasing the number of scrapings from 3 to 4 did not increase the cell yield. The same method has been used to collect early plaque formed on different materials [21]. The experiments were performed with 3-4 replicates and repeated at least once.

For the enumeration of cells on the disc surfaces as colony forming units (CFU) the vials with the microbe samples collected from the surfaces were thoroughly Vortex-treated and after serial dilutions of the samples grown anaerobically for 2 days at $+37^{\circ} \mathrm{C}$ on Mitis salivarius agars (Difco).

In some experiments the materials were subjected to fixation followed by scanning electron microscope (SEM) as described below.

\section{SEM}

For the SEM examinations the samples were fixed for 5 min $(2 \%$ glutaraldehyde and $2 \%$ formaldehyde in phosphatebuffered saline [Orion Diagnostica, Espoo, Finland], $\mathrm{pH}$ 7.4), rinsed once in distilled water and dried in an ascending ethanol series: $50 \% \mathrm{EtOH}$ for $5 \mathrm{~min}, 70 \% \mathrm{EtOH}$ for $10 \mathrm{~min}$, two times $96 \% \mathrm{EtOH}$ for $10 \mathrm{~min}$ and absolute EtOH for 5 min. Finally the specimens were sputter coated with gold and examined with SEM (Model JSM 5500, JEOL Ltd., Tokyo, Japan). 


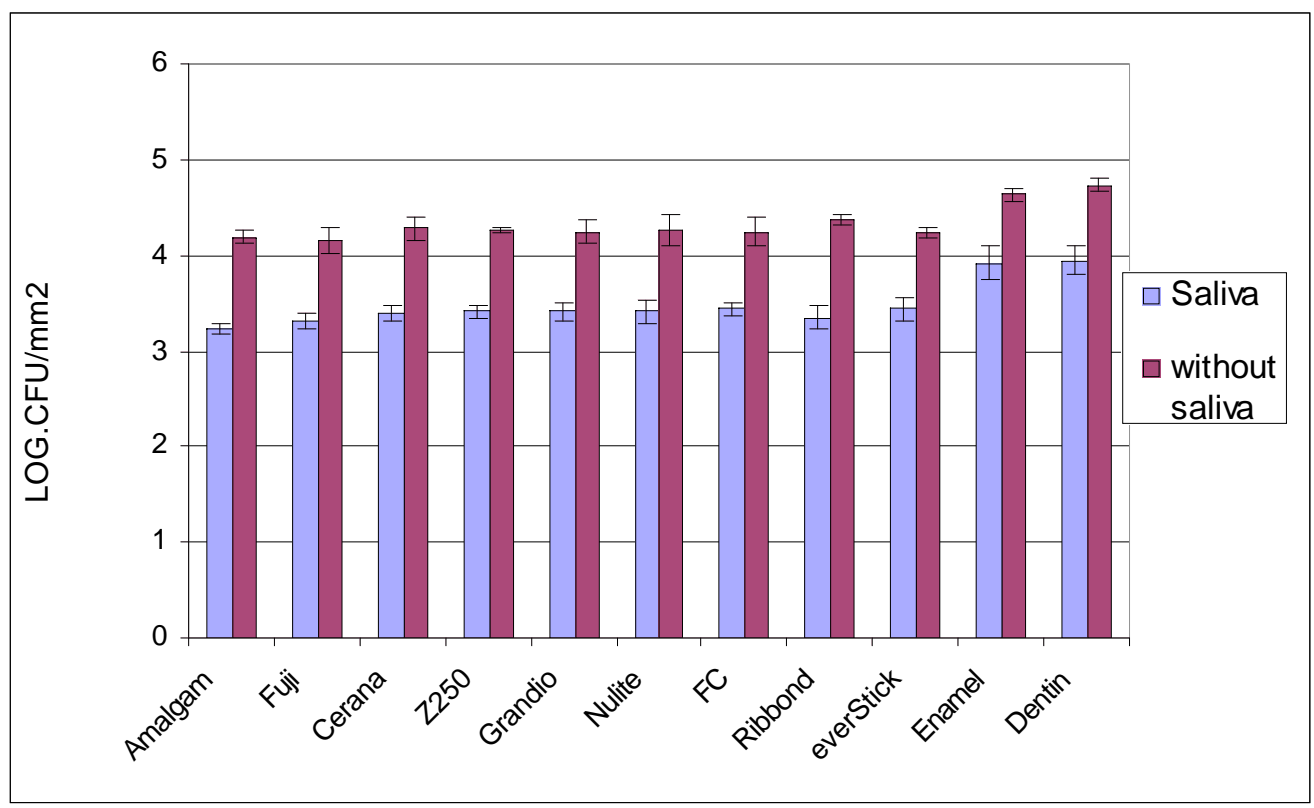

Fig. (2). Number of adhered S. mutans cells on tested restorative materials with and without saliva surface precoating. Vertical lines represent standard deviations. Horizontal line above the bars indicates groups that statistically differ from others.

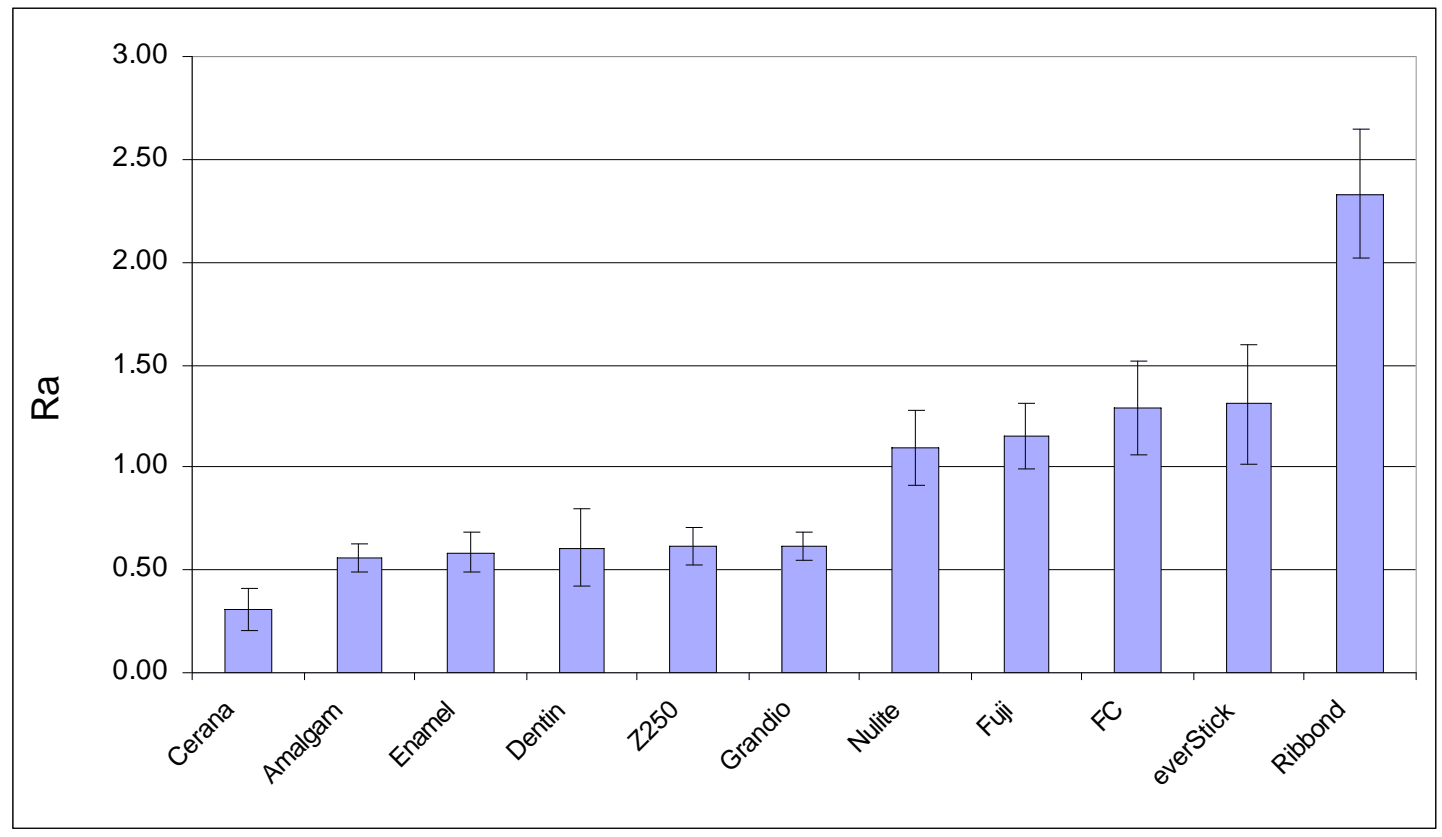

Fig. (3). Mean $\mathrm{Ra}(\mu \mathrm{m})$ values of the materials tested. Vertical lines represent standard deviations. Horizontal line above the bars indicates groups that do not differ statistically from each other.

\section{STATISTICAL ANALYSIS}

The results were statistically analyzed with analysis of variance (ANOVA) at the $\mathrm{P}<0.05$ significance level with SPSS version 13 (Statistical Package for Social Science, SPSS Inc, Chicago, IL, USA). Subsequent multiple comparisons were conducted using Tukey's post hoc analysis.

\section{RESULT}

Experimental composite $\mathrm{FC}$ resin and other tested materials showed similar adhesion of $S$. mutans (Fig. 2), while adhesion to dentin and enamel was significantly higher $(\mathrm{p}<0.05)$.

Saliva coating significantly decreased the adhesion for all materials but dentine and enamel still showed the highest $S$. mutans adhesion.

No relation was found between surface roughness and $S$. mutans adhesion. Significant differences were detected in the surface roughness of studied materials (Fig. 3). The lowest $\mathrm{Ra}$ value was obtained with specimens made from Cerana class $1(0.31 \mu \mathrm{m} \pm 0.1)$ and specimens made from Ribbond 
had highest values $(2.33 \mu \mathrm{m} \pm 0.31)$. Experimental composite FC resin had a significantly higher Ra value than control groups $(\mathrm{p}<0.05)$.

Scanning-electron microscopy of bacteria binding to noncoated and saliva-coated specimens revealed less bacteria on the specimens after saliva coating.

\section{DISCUSSION}

Bacterial colonization of $S$. mutans is usually the first step leading to secondary caries development. Adhesion of $S$. mutans to short fiber composite FC resin and different commercial restorative materials were studied in relation to surface roughness.

Based on the results of the present in vitro study S. mutans does not demonstrate difference adhesion to experimental composite FC resin than to other restorative materials tested (Fig. 2), despite of different surface roughness they have. Interestingly, adhesion of $S$. mutans was previously shown to increase with increasing surface free energy $[9,21]$. However, glass fibers with higher surface energy seemed to adhere same $S$. mutans than the restorative materials with lower surface energy. Our findings are in agreement with a studies by Tanner et al., which showed that glass fiberreinforced composite (FRC) resembles restorative composite with respect of plaque accumulation and adherence of $S$. mutans [21,22]. Our observations clearly demonstrated no influence of surface roughness on $S$. mutans adhesion. This is in accordance with Eick et al., who demonstrated that no correlation found between surface roughness and the number of colony forming units (CFU) of S. mutans [23].

Enamel and dentin demonstrated higher bacterial adhesion than tested restorative materials. This is most likely due to hydrophobic interaction of tooth structure. Several authors showed the influence of saliva pellicle on the degree of bacterial adhesion in comparison with uncoated surfaces [24$26]$. The results of the present study support these observations showing a lower degree of $S$. mutans binding after saliva coating on all tested materials.

Methodologically, one limitation of the present study is related to the scraping test of the cells and not labeling of them since we wanted to collect both sides of the material specimens. However, repeatability of the scraping method was good as judged by the small standard deviations of the replicates. This enabled also the assessment of CFUs and SEM detection from the same specimen.

The SEM was not a valid method to study the attachment since most materials were too uneven for SEM. Scanning results were in agreement with the scrapings (Fig. 2) to demonstrate how homogenous the bacterial suspension was with no S. mutans chains.

Mechanical profilometers have been used to measure surface roughness for in vitro investigations. The profilometers provide somewhat limited two-dimensional information. As apparent in Fig. (3), there were proportional significant differences between the Ra values of different restorative materials. The Ra value of composite $\mathrm{FC}$ resin was at same level to the commercial packable composite resin (Nulite) and resin-modified glass ionomers (Fuji II LC). On the other hand, Grandio and Z250 as hybrid composite resins revealed lower $\mathrm{Ra}$ value than other composite resins. However, the $\mathrm{Ra}$ value of short fiber reinforced composite resin was within the clinical acceptable range $[27,28]$. Roughness can be related to a combination of factors that include the characteristics of the matrix, ratio and size of inorganic particles, exposition of these inorganic particles and formation of air bubbles during material preparation. FC, Nulite and Fuji resins present the higher mean particle size according to manufacturer data. In contrast, Z250 and Grandio contain a smaller range of filler particles size than other composites tested, which may partially explain the lower roughness obtained with this composite resin. In addition, resin composite filler particles appear to play an intrinsic role in how well a composite finishes. In composites where the filler particles are significantly harder than the matrix, the resin phase may suffer a special loss during finishing. This will result in the positive relief of filler particles on the surface $[29,30]$.

Another aspect reported in the literature that may have an influence on the surfaces roughness is finishing and polishing techniques $[28,29]$. However, in this study all specimens were finished to closely simulate clinical conditions, i.e. by using diamond-finishing cup. Moreover, finishing time, and press-on force should also be taken into consideration [31].

Based on the results of this study and our previous published data of short fiber composite resin [15, 32-34], it is suggested that experimental FC composite could be used successfully to fulfill the requirements for a posterior restoration. However, it should be emphasized that clinical trials are necessary in order to evaluate the usefulness of FC composite resin in dental restorations.

\section{CONCLUSIONS}

The new experimental short-fiber composite does not change the $S$. mutans adhesion tendency, although surface roughness values were higher than for commercial composite resin.

\section{ACKNOWLEDGMENT}

The authors gratefully acknowledge Mrs. Milla Lahdenperä, Ms. Jasmina Bijelic, and Ms. Oona Hällfors for kind help in this study.

\section{REFERENCES}

[1] Ferracane JL, Berge HX, Condon JR. In vitro aging of dental composites in water-effect of degree of conversion, filler volume, and filler/matrix coupling. J Biomed Mater Res 1998; 42: 465-72.

[2] Watts DC, Hindi AA. Intrinsic soft-start polymerization shrinkagekinetics in an acrylate-based resin composite. Dent Mater 1999; 15: $39-45$.

[3] Petersen RC. Discontinuous fibre-reinforced composites above critical length. J Dent Res 2005; 84: 365-70.

[4] Garoushi S, Lassila LVJ, Tezvergil A, Vallittu PK. Load bearing capacity of fibre-reinforced and particulate filler composite resin combination. J Dent 2006; 34: 179-84.

[5] Garoushi S, Lassila LV, Tezvergil A, Vallittu PK. Static and fatigue compression test for particulate filler composite resin with fiber-reinforced composite substructure. Dent Mater 2007; 23: 17-23.

[6] Xu HHK, Quinn JB, Smith DT, Giuseppetti AA, Eichmiller FC. Effect of different whiskers on the reinforcement of dental resin composites. Dent Mater 2003; 19: 359-67.

[7] Zandinejad AA, Atai M, Pahlevan A. The effect of ceramic and porous fillers on the mechanical properties of experimental dental composites. Dent Mater 2006; 22: 382-7. 
[8] Tian M, Gao Y, Liu Y, Liao Y, Hedin NE, Fong H. Fabrication and evaluation of Bis-GMA/TEGDMA dental resins/composites containing nano fibrillar silicate. Dent Mater 2008; 24: 235-43.

[9] Brambilla E, Cagetti MG, Gagliani M, Fadini L, Godoy FG, Strohmenger L. Influence of different adhesive restorative materials on mutans streptococci colonization. Am J Dent 2005; 18: 1736.

[10] Sbordone L, Bortolaia C. Oral microbial biofilms and plaquerelated diseases: Microbial communities and their role in the shift from oral health to disease. Clin Oral Investig 2003; 7: 181-8.

[11] Vallittu PK. A review of fibre-reinforced denture base resins. J Prosthodont 1996; 5: 270-6.

[12] Vallittu PK, Narva K. Impact strength of a modified continuous glass fibre-poly (methyl methacrylate). Int J Prosthodont 1997; 10: 142-8.

[13] Lastumäki TM, Lassila LV, Vallittu PK. The semi-interpenetrating polymer network matrix of fibre-reinforced composite and its effect on the surface adhesive properties. J Mater Sci Mater Med 2003; 14: 803-9.

[14] Lassila LV, Tezvergil A, Lahdenperä M, Alander P, Shinya A, Vallittu PK. Evaluation of some properties of two fibre reinforced composite materials. Acta Odontol Scand 2005; 63: 196-204.

[15] Garoushi S, Vallittu PK, Lassila LVJ. Short glass fiber reinforced restorative composite resin with semi-interpenetrating polymer network matrix. Dent Mater 2007; 23: 1356-62.

[16] Garoushi S, Vallittu PK, Lassila LVJ. Use of isotropic short fiber reinforced composite with semi-interpenterating polymer network matrix in fixed partial dentures. J Dent 2007; 35: 403-8.

[17] Garoushi S, Vallittu PK, Lassila LVJ. Fracture resistance of short, randomly orineted, glass fiber-reinforced composite premolar crowns. Acta Biomater 2007; 3: 779-84.

[18] Keulemans F, Lassila LV, Garoushi S, Vallittu PK, Kleverlaan CJ, Feilzer AJ. The influence of framework design on the loadbearing capacity of laboratory-made inlay-retained fiberreinforced composite fixed dental prostheses. J Biomech 2009; 42: 844-9.

[19] Söderholm KJ, Yang MC, Garcea I. Filler particle leachability of experimental dental composites. Eur J Oral Sci 2000; 108: 555-60.

[20] Olsson J, Carlen A, Holmberg K. Inhibition of streptococcus mutans adherence to hydroxyapatite with combinations of alkyl phosphates and nonionic surfacetants. Caries Res 1991; 25: 51-7.

[21] Tanner J, Robinson C, Söderling E, Vallittu PK. Early plaque formation on fiber-reinforced composites in vivo. Clin Oral Invest 2005; 9: 154-60.
[22] Tanner J, Carlen A, Söderling E, Vallittu PK. Absorption of parotid saliva protiens and adhesion of streptococcus mutans ATCC 21752 to dental fiber-reinforced composites. J Biomed Mater Res Part B Appl Biomater 2003; 66: 391-8.

[23] Eick S, Glockmann E, Brandl B, Pfister W. Adherence of Streptococcus mutans to various restorative materials in a continuous flow system. J Oral Rehabil 2004; 31: 278-85.

[24] Larsson K, Glantz PO. Microbial adhesion to surfaces with different surface charges. Acta Odontol Scand 1981; 39: 79-82.

[25] Tanner J. Adhesion of oral microbes to dental fiber reinforced composite with emphasis on Streptococcus mutans and Candida albicans. Thesis, University of Turku, Finland 2003.

[26] Satou J, Fukunaga A, Morikawa A, Matsumae I, Satou N, Shintani H. Streptococcal adherence to uncoated and saliva coated restoratives. J Oral Rehabil 1991; 18: 421-9.

[27] Uctasli MB, Bala O, Gullu A. Surface roughness of flowable and packable composite resin materials after finishing with abrasive discs. J Oral Rehabil 2004; 31: 1197-202.

[28] Barbosa SH, Zanata RL, Navarro ML, Nunes OB. Effect of different finishing and polishing techniques on the surface roughness of microfilled, hybrid and packable composite resins. Braz Dent J 2005; 16: 39-44.

[29] Uctasli MB, Arisu HD, Omurlu H, Eliquzeloglu E, Ozcans S, Erqun $\mathrm{G}$. The effect of different finishing and polishing systems on the surface roughness of different composite restorative materials. J Contemp Dent Pract 2007; 8: 89-96.

[30] Turssi CP, Ferracane JL, Serra MC. Abrasive wear of resin composites as related to finishing and polishing procedures. Dent Mater 2005; $21: 641-48$.

[31] Heintze SD, Forjanic M, Rousson V. Surface roughness and gloss of dental materials as a function of force and polishing time in $\mathrm{vi}$ tro. Dent Mater 2006; 22: 146-65.

[32] Garoushi S, Vallittu PK, Watts DC, Lassila LVJ. Polymerization shrinkage of experimental short glass fiber reinforced composite with semi-inter penetrating polymer network matrix. Dent Mater 2008; $24: 211-5$.

[33] Garoushi S, Vallittu PK, Lassila LVJ. Effect of storage time on Microtensile bond strength of short glass fiber reinforced composite. Chin J Dent Res 2007; 10: 7-10.

[34] Garoushi S, Vallittu PK, Lassila LVJ. Continuous and short fiber reinforced composite in root post-core system of severely damaged incisors. Open Dent J 2009; 3: 36-41.

(C) Lassila et al.; Licensee Bentham Open.

This is an open access article licensed under the terms of the Creative Commons Attribution Non-Commercial License (http://creativecommons.org/licenses/by-nc/3.0/) which permits unrestricted, non-commercial use, distribution and reproduction in any medium, provided the work is properly cited. 